\title{
Embodied Learning Implementation in EFL Classroom: A Qualitative Study
}

\author{
Kanar Zirak Haseeb Chicho ${ }^{1}$
}

${ }^{1}$ English Language Teaching Department, Education Faculty, Tishk International University, Erbil, Iraq Correspondence: Kanar Zirak Haseeb Chicho, Tishk International University, Erbil, Iraq.

Email: kanar.zirak@tiu.edu.iq

\section{Doi: 10.23918/ijsses.v8i1p51}

\begin{abstract}
Motivating students for learning a foreign language in classrooms needs several updated techniques, strategies, and methods. Modern methods and approaches play important roles in language teaching in a learning environment. Recently, Embodied learning, as one of the modern approaches shows its effectiveness on developing speaking skills in foreign language classes. Embodied learning means the connection between bodily movements during the activities and cognitive ability; it adds a modern pedagogical theory of learning which shows the role of body in education and learning. This paper aims to investigate the effectiveness of embodied learning in educational practice in teaching English as a foreign language in Erbil, Kurdistan Region. Data were collected from language learners through interviews. The students' responses, motivation and development were analysed in the data analysis. It was found that embodied learning affects the learners to be more motivated to learn the language also reinforces them to use the target language effectively in the classroom.
\end{abstract}

Keywords: Embodied Learning, Learning Theories, Motivation, Language Development

\section{Introduction}

This paper describes the effectiveness of embodied learning in educational practices in teaching English as foreign language classes. Embodied learning is one of the innovative pedagogies that provides a modern pedagogical theory of teaching. In embodied learning classes, the use of the body in the educational practice is emphasized. The student-teacher interaction in embodied learning class is more effective and powerful. This interaction is maintained through communication both inside and outside the classroom. The teacher of embodied class can interact with the students in digital environments as well. Using body and gestures in this method is considered as a significant learning tool; for instance, most students can learn while they are moving during interactions and communication (Channon \& Khomutova, 2018)

Previously the physical movements had no role and impact in the process of education. Their usage had been consistently excluded from the educational practice (Kosmas, Ioannou, \& Zaphiris, 2019). In the interaction among students, they were omitted. The concept of embodied learning was unknown for teachers and students then; therefore, it was problematic to understand that the body does not exclusively establish a means of information, or a mediator, but it also encourages students' communication in their environment.

Received: October 11, 2020

Accepted: January 27, 2021

Chicho, K.Z.H. (2020). Embodied Learning Implementation in EFL Classroom: A Qualitative Study. International Journal of Social Sciences \& Educational Studies, 8(1), 51-58. 
Embodied learning somehow has relation with constructivist models. Embodied education is defined as the concept of embodied teaching and embodied learning which provides several activities in language classrooms. The terms embodied learning and embodied teaching make it clear that body is needed during language learning. The approach is also referred to innovative scientific and educational practices (Schmidt, 2019).

According to the constructivist model, the body has been used in the classroom for the sake of empirical learning, but it is not considered as a place of learning. The concept of embodied learning delivers responses to questions which are connected to the methods of teaching. In embodied learning, knowledge and information has been affected by the circumstances. This approach is used with different types of activities in which the students are expected to participate. Accordingly, the below boundaries need be taken into consideration in the process of conducting activity:

1. Mental involvement to the topic and to the illustration of a scientific concept

2. Body activities

3. Appearance of the learner's emotions

4. Clearness of instructions

5. All-inclusive design of activities

6. Student collaboration

7. Talent of students to use the acquired knowledge to be adapted to the new environments.

It has been approved that embodied learning takes actions with the accordance of modern educational practices, and uses and applies characters as a whole. It also encourages the students to acquire the knowledge in an effective way. On the other hand, there are few studies that have been conducted to connect Embodied learning to the performance of educational practice. Embodied learning aims to improve student's creativity, the skill of critical thinking, and their productivity. This method makes the learners think deeply to understand the scientific notions and phenomena with the connection of the sciences to forms of art. The present study aims to highlight the impacts of embodied learning in educational practices, and to explore how this approach can change students' position from passive receivers to active participants in the classroom (Foglia, \& Wilson, 2013).

\section{Literature Review}

\subsection{Definitions of Embodied Learning}

Embodied learning is defined as the connection between bodily movements and cognitive abilities. Embodied learning shows the relation among movements and academic achievement; in other words, it is the relation of mind and body (Foglia, \& Wilson, 2013). Embodied learning makes the learners investigate more about knowledge because they use the knowledge that they acquired. Horn and Wilburn (2005) stated that embodied learning omits the old methods that focus on transforming knowledge and brings new views into target language teaching. It is worth to say that embodied classroom is full of activities and exercises; thus, most of the time language learners work in a coordinated way. During the activities the students are guided to randomly and unconsciously movements. They are in the process of competition and linked with the content. Those movements make the learners develop the level of comprehension and embodiment of new knowledge. The brain in embodied learning classroom is almost active because the body is active. 
The cognition is usually in the process of sending and receiving messages. The network of all momentary actions is thus gradually constructed which leads to embodied learning (Smyrnaiou \& Kynigos, 2012).

Additionally, teacher-student interaction in the class has important roles in embodied learning. That is why students may affect each other in terms of personality and character development. By observing these cooperation and interactions, the learners learn from their experiences and complete each other. Cooperation is an element to bring the different learners to work in the same activity to express their opinions and interact with each other (Meena, 2020). Interactions and communication increase the learning outcomes (Mart, 2018). In addition, they also provide encouragement and motivation for more expansion and development. In embodied learning classroom the teacher achieves her/his goals affectively because the students are highly motivated and encouraged to apply what they learn. To put it in another way, learning progresses in a quite positive environment (Segal, 2011).

With the fact that embodied learning has the relation with the improvement of creative skills, it makes the learners enhance critical thinking skills. The learners are active participants in rendering and deeply understanding the scientific concepts. They deeply understand the phenomena and the scientific interconnection of sciences to arts (Dixon \& Senior, 2011).

Embodied learning includes:

a) The illustration of scientific concepts (linking movement to concept). It means that body has effects and impacts in scientific notions. It makes the learners motivate in the process of acquiring language.

b) Art (dance movements in the process of education, humor in movements during class hours), body. In embodied learning classroom arts, movements, talents, and desire show their power and impacts in the classroom. This combination makes the learners be more courageous to speak in the target language.

c) Unconscious movements during responding and answering questions makes the learners use the target language unconsciously.

\section{Methodology}

\subsection{Participants}

The population of this study are fifteen students who were selected randomly. They are from Erbil. Their ages are (20-26) and they are beginner learners (according to the proficiency test they had in the language centre of the university where the current study was conducted). They are in a training course of English for specific purpose. Nine of them are females, and seven of them are males. Their qualifications are different. While some of them are students, some of them have completed their education. However, they all have the same goal which is leaning the English language well and speak it fluently and accurately. They were treated with embodied learning for seven weeks. At the beginning of the study, they were informed about the study and they all accepted to be a part of it. 


\subsection{Research Context}

The present study is a qualitative research. The data is collected from a structured interview (see appendix A) with students who were treated with embodied learning. The interview questions which were prepared by the researcher was conducted according to the aim and hypothesis of the research. The students' responses were recorded and then transcribed. The responses were categorized. The researcher started the research project by applying the strategies of embodiments. After the treatment, the researcher started the interview in the classroom which was done individually. Each interview took 5-7 minutes.

\subsection{Procedure}

The current research stands for exploring the effectiveness of the embodied learning on improving speaking in EFL classroom. For conducting the present research, first of all, the participants were selected randomly. Later, the researcher followed the ethical issues and informed the students about the study and they accepted to be a part of it. The participants' names are not mentioned and the collected data were only used in this study. The seven weeks of the treatment session started, and the students were treated with the strategies of embodiment. The first week, under the refresher's supervision, the students were involved in role making activities. They performed drama of how to make conversation with people whom they have met recently. They came to the centre of the class and started to speak in the target language. In the following weeks, different topics were used such as how to tell an address, how to order food in a restaurant, how to book tickets in a station, and how to ask about the price of things during shopping. For each topic the strategies of embodied learning were applied, for example, while showing the address the students were given maps and were asked to use their hands to show the turns. On the last week of the treatment session, the students had an interview. The interview was done in the classroom. Each student met the researcher individually. The students' responses were recorded by the researcher.

\subsection{Data Analysis}

After the interview, the participants' responses were transcribed immediately. Then the transcripts were read several times. Later, they were categorized into themes. These themes were shown as comments and opinions. The collected data were then analysed. The collected data were used to achieve a general idea from the learners about how embodied learning makes the learners use the target language, and how it makes the leaners participate actively inside the class. Three major categories were taken into consideration. Motivation, confidence and self-development are the three major concepts that were measured. How the students are motivated to use the target language, how embodied learning makes them show a high self-esteem during making conversation in the foreign language, and finally how the students from passive listeners become active participants are explored in the present study. The participants' responses towards embodied learning were mainly focused on the mentioned categories.

\section{Results and Discussion}

According to the learners' responses during the interview, it was found that embodied learning motivates students to use the target language because it provides different activities and tasks such as role making. In embodied learning classroom most of the language learners are highly motivated to be a part of the activity. Furthermore, the activities they were engaged in enabled them to gain confidence and self- 
development. It can be said that embodied leaning has changed learner' perception towards speaking in the target language.

Table 1: Major Categories

\begin{tabular}{|l|l|}
\hline Major Categories & Associated Concepts \\
\hline Motivation & The usage of the target language \\
\hline Confidence & $\begin{array}{l}\text { Self-esteem during classroom } \\
\text { activities }\end{array}$ \\
\hline Self - Development & Becoming active learners \\
\hline
\end{tabular}

Table 1 shows the major categories with associated concepts, which are collected from the students' interview.

\subsection{Motivation}

Embodied learning approach spawns motivation and encouragement to participate in classroom activities. Most of the participants in this study claimed that embodied learning approach has increased their motivation to participate in classroom activities and discussions. It is important to note that classroom discussions make language learners replace their roles from knowledge consumers to knowledge constructors (Mart, 2019). The present study is consistent with the study which was conducted by Kosmas, Ioannou and Zaphiris (2019) who found that embodied learning has the potential to motivate learners for better learning. Some of the participants said that:

"I used to feel less motivated when I was in the class. I was asking my classmates to translate the target language to my native language, because it was very difficult for me. But embodied learning approach switched me to a passionate person to use the target language, and it made me be more motivated to participate in classroom discussions". (Student A)

"Embodied learning approach changed my perception towards the learning. Previously, I thought that studying a language was very boring and difficult, but now I totally I think that language learning is more interesting when it happens naturally". (Student E)

\subsection{Confidence}

Confidence is a significant tool that triggers learning. In embodied learning classroom students can expand their confidence. The use of movements and reactions allow them to have a high self-esteem. It is possible to say that embodied learning can arouse a desire to learn better. It goes without saying that teachers have primary responsibility to motivate learners (Mart, 2011). With this in mind, the use embodied learning approach in the classroom can motivate students to learn. One of the participants said that:

"I used to feel less confident while I was speaking in English in the class. I was worried about how my classmates think about my performance. It was very difficult for me to get 
over with this fear. Luckily, embodied learning made me feel more confident. Now I start to get rid of that negative idea". (Student F)

\subsection{Self- Development}

Embodied learning approach has enhanced critical thinking development of learners by engaging them in exercises and practices. Embodied learning benefits learners for developing awareness and intellectual improvement. The findings in the current research aligns with the study which was conducted by Fugate, Macrine and Cipriano (2019) who found that embodied learning opens the door of self-development and improvements. One of the participants said:

"I enjoyed classroom activities and tasks, especially group tasks. My classmates helped me a lot in speaking and discussion. We collaborated with each other and this helped me to improve my social skills". (Student C)

Few participants had negative ideas about the impacts of embodied learning approach in self-development. Negative view that was shared by the participants was that the use of embodied learning hindered their self-improvement.

"The classroom environment was new for me. It was not easy for to be adapted and do well. I was expecting the teacher to explain the subject in a different way rather than teaching us with activities". (Student D)

\section{Conclusion}

The aim of the current study was to show the role and impact of embodied learning in educational practices. The current study yielded that the use of embodied learning can help learners develop motivation, confidence and self-development.

- It was found that embodied leaning approach presents effective factors for enabling the language learners to develop themselves. Students in the embodied learning classroom showed a high improvement in their learning process.

- Embodied learning is an important method that needs to be applied and performed in the EFL class. It consists of different activities, tasks exercises, and resources which make the learner be motivated to speak in the target language.

- Embodied learning in this research made the learners control their shyness, anxiety, and stress. The activities and routines that were used and performed by the instructor foster confidence and energy of learners and pave the way for improving their social and interactional skills.

- Embodied learning enabled students to be active learners; furthermore, the use of the approach encouraged them to participate more in group activities.

- Embodied learning increased self-confidence of learners. They were highly motivated and eager to use the target language. 


\section{References}

Barzani, S. H. H. (2020). The perceptions of EFL teachers and students on the use of short stories to enhance reading comprehension. Asian EFL Journal 27(3.1), 325-341.

Channon, A., Matthews, C. R., \& Khomutova, A. (2018). Moving lessons: Teaching sociology through embodied learning in the HE classroom. In Teaching with sociological imagination in higher and further education (pp. 135-151). Springer, Singapore.

Dixon, M., \& Senior, K. (2011). Appearing pedagogy: from embodied learning and teaching to embodied pedagogy. Pedagogy, Culture \& Society, 19(3), 473-484.

Foglia, L., \& Wilson, R. A. (2013). Embodied cognition. Wiley Interdisciplinary Reviews: Cognitive Science, 4(3), 319-325.

Kosmas, P., Ioannou, A., \& Zaphiris, P. (2019). Implementing embodied learning in the classroom: effects on children's memory and language skills. Educational Media International ,56(1), 5974.

Mart, Ç.T. (2011). How to sustain students' motivation in a learning environment. Retrieved from ERIC database: ED519165.

Mart, Ç.T. (2018). From communicative competence to language development. International Journal of English Linguistics, 8(2), 163-167.

Mart, Ç.T. (2019). Reflections on discussions of literature: A language learning environment to promote speaking skills. The Journal of Social Sciences Research, 5 (4), 846-850.

Meena, R. S., \& Altun, M. (2020). The effect of cooperative learning strategies in the enhancement of EFL learners' speaking skills. Asian EFL Journal Research Articles, 27.

Schmidt, M., Benzing, V., Wallman-Jones, A., Mavilidi, M. F., Lubans, D. R., \& Paas, F. (2019). Embodied learning in the classroom: Effects on primary school children's attention and foreign language vocabulary learning. Psychology of Sport and Exercise, 43, 45-54.

Segal, A. (2011). Do gestural interfaces promote thinking? Embodied interaction: Congruent gestures and direct touch promote performance in Math. Unpublished PhD thesis, New York: Columbia University.

Smyrnaiou, Z. G., \& Kynigos, C. (2012). Interactive movement and talk in generating meanings from science. Bulletin of the IEEE Technical Committee on Learning Technology, 14(4), 17. 


\section{Appendix A}

\section{Interview Questions}

1. How was your performance during the course?

2. In your view, does the use of embodied learning method develop your linguistic proficiency?

3. How did you change your attitudes towards speaking English thought the course?

4. Do you think that embodied learning approach is a good method to be applied in language classes? Why?

5. Do you think the use of embodied learning develops your communicative competence in language classes? How?

6. Do you think the use of embodied learning in language classes can be considered successful?

7. Do you think this experience will help you control over your own language learning? 